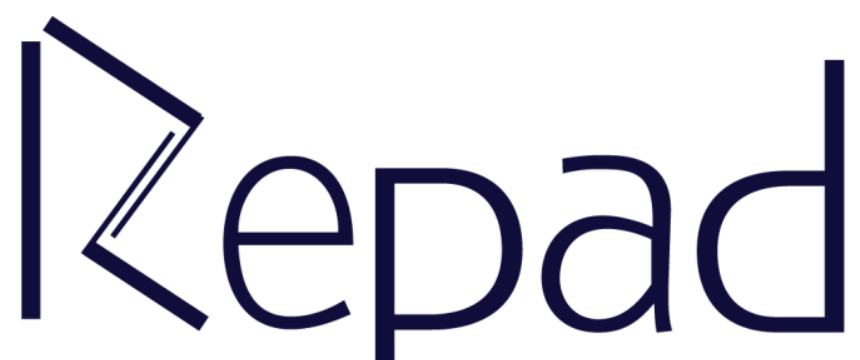

Vol. 2, n 2, AGOSTO/2018

Revista Estudos e

Pesquisas em Administração

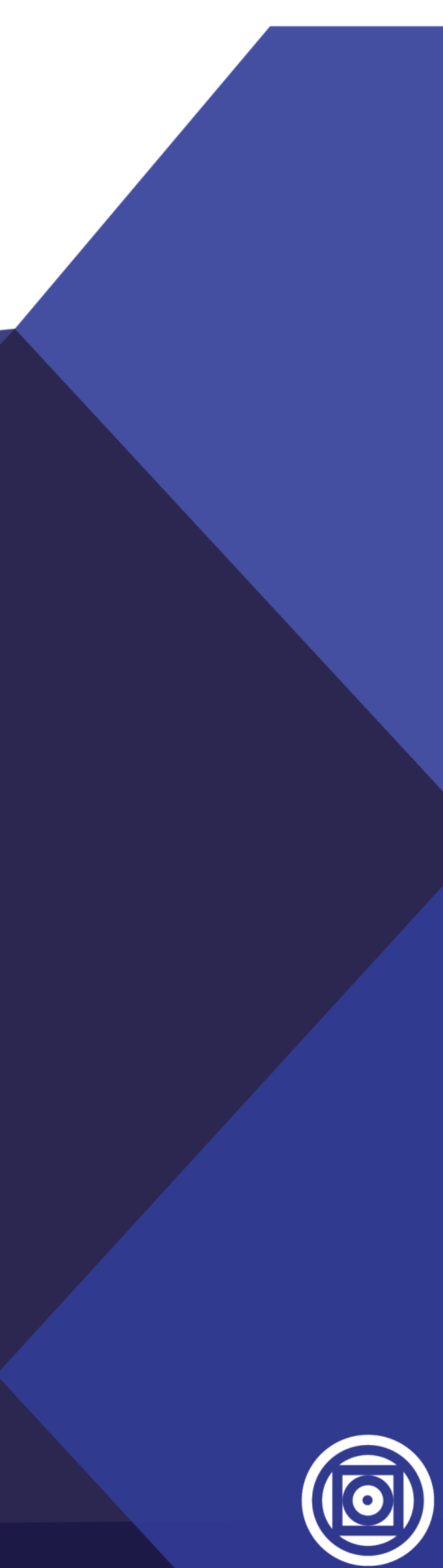




\title{
EVASÃO UNIVERSITÁRIA NO ENSINO À DISTÂNCIA: Análise dos fatores influenciadores
}

\section{UNIVERSITY EVASION IN DISTANCE LEARNING: Analysis of factors influencing}

\author{
Thais Santos Martins \\ Universidade Federal de Mato Grosso \\ https://orcid.org/0000-0001-7023-6295
}

\begin{abstract}
RESUMO
A discussão sobre o tema evasão universitária tem sido uma realidade recorrente na área da Educação no Brasil e em várias partes do mundo. Nesse contexto, assume centralidade o ensino à Distância, pois tem sido considerada uma alternativa de acesso ao ensino superior. Assim, este trabalho tem por objetivo analisar as principais razões de evasão nos 18 cursos do polo de educação à distância da Anhanguera - Uniderp na cidade de Rondonópolis-MT. A coleta de dados foi realizada em dois momentos. Primeiramente, por meio de entrevistas semiestruturadas com o diretor e os coordenadores dos cursos, e depois, por meio de um questionário eletrônico enviado aos alunos. No tratamento dos dados foram utilizados modelos estatísticos abrangendo análise fatorial e comparativo entre médias. Os resultados indicam que há diferenças, estatisticamente significativas a um nível de 0,05 , entre as razões de evasão e a situação quando estudava, o estado civil, e que não há diferenças, estatisticamente significativas, entre as razões de evasão e o semestre, o curso, o gênero e o tipo de moradia. Os dados qualitativos apresentam algumas razões não observadas antes. Os resultados das análises quantitativas e qualitativas foram discutidos, conjuntamente, de maneira a reforçar as descobertas desta pesquisa.
\end{abstract}

Palavras-chave: Educação; Ensino à distância; Evasão.

\begin{abstract}
The theme of the evasion on higher education has become a real concern and a reality in Brazil's educational area and other parts of the world. In this context, Distance Learning assumes the centrality, because it has been considered an alternative to get access to higher education. Thus, the objective of this paper is to analyze the main reasons for the evasion in 18 courses of the Distance Learning Hub at Anhanguera Uniderp in Rondonópolis - MT. The data collection took place in two moments. First, by semi-structured interviews with principals and coordinators of the institution, later, by sending an electronic questionnaire to students. During the consideration of the data, statistic models were used covering factorial and comparative analysis between average numbers. The results show significant statistic differences at 0,05 level between the evasion and the situation when these students were studying and marital status, and there is no significant difference between evasion and semester, course, gender and type of housing. Qualitative data have some reasons not observed before. The results of the quantitative and qualitative analysis were discussed together, with the purpose to reinforce the discoveries of the research.
\end{abstract}

Keywords: Education; Distance Learning System; Evasion.

Recebido em 20/07/2018 e aprovado em 21/08/2018 


\section{CONSIDERAÇÕES INICIAIS}

O tema evasão é uma realidade recorrente da educação no Brasil e em várias partes do mundo. $\mathrm{O}$ estudo desse fenômeno tem sido alvo de pesquisas para compreender quais são os motivos que levam esses alunos a deixarem de cursar o ensino superior. Evasão pode ser compreendida, de modo geral, como o abandono do aluno em algum momento do curso que está fazendo. Nesse contexto, assume centralidade a Educação à Distância, tema deste estudo.

A Educação à distância é uma modalidade de ensino e aprendizagem que tem atingido maior relativa credibilidade no ensino superior, pois ocorre com atualização da tecnologia de informação e comunicação o que tende a facilitar as atividades de ensino presencial, há certa taxa de alunos que desistem e não concluem seus cursos.

O sistema educacional está sentindo nos últimos anos os reflexos da inovação, por exemplo, com possibilidade de uso da internet para a criação de rede de computadores em ambientes virtuais de aprendizagem. Os cursos à distância apresentam vários aspectos que propiciam a flexibilidade aos alunos, como a autonomia do estudando para coordenar sua a aprendizagem e o acesso a conteúdo a qualquer tempo e de qualquer local. Mas essa modalidade de ensino tem passado por desafios, como a dificuldade do aluno em acompanhar o cronograma de estudos e os problemas com o uso da tecnologia. Esse novo paradigma tem como proposta a ampliação e a democratização da educação, contudo essa modalidade ainda passa pelo período de mudança cultural e tem produzido alguns insucessos. A literatura registra altas taxas de evasão de alunos, mostrando que muitos iniciam o curso, mas não consegue completá-los.

A relevância de saber mais a respeito sobre o tema é que a pesquisa sobre a evasão em cursos à distância ainda é escassa tanto na literatura nacional, como na estrangeira e precisa se r mais explorada. São poucos os estudos feitos anteriormente sobre o tema como os de Lacerda (2013), Moreira et al. (2013), Abbad et al. (2006), Walter (2008), Almeida (2008), Netto (2012), Almeida (2013), Silveira (2012), Pacheco (2015), onde buscam desvendar as razões que levariam os alunos a desistir do curso superior. Fatores situacionais; falta de apoio acadêmico; problemas com a tecnologia; e falta de apoio administrativo são uns dos principais motivos indicados por esses estudos. Dessa forma, tornam-se necessárias investigações sobre os fatores que levam os alunos a abandonarem seus cursos à distância de forma a corroborar ou não com poucos estudos encontrados na literatura.

Assim, este trabalho teve por objetivo analisar as principais razões de evasão nos 18 cursos do polo de educação à distância da Anhanguera Uniderp na cidade de Rondonópolis MT, considerando o período de 2007 (ano de abertura da Universidade em Rondonópolis) a julho de 2016 e os fatores demográficos de seus alunos.

Os objetivos específicos buscam comparar as razões de evasão com as variáveis gênero, moradia, situação quando estava estudando, estado civil, semestre e curso. E para esta pesquisa, foram lançadas seis hipóteses diferentes, relacionando as diferenças entre as razões de evasão e os aspectos demográficos. As hipóteses são:

H1. Há diferenças entre razões de evasão de acordo com o gênero;

H2: Há diferenças entre as razões de evasão e a moradia; estudando;

H3: Há diferenças entre as razões de evasão e situação do aluno quando estava

H4: Há diferenças entre as razões de evasão e o estado civil;

H5: Há diferenças entre as razões de evasão e os semestres em que os alunos deixaram o curso;

H6: Há diferenças entre as razões de evasão e o curso em que o aluno estava matriculado; 
A coleta de dados foi realizada em dois momentos, por meio de entrevistas semiestruturadas com o diretor e os coordenadores dos cursos e por meio de um questionário enviado aos alunos entre os dias 28/07/2016 e 28/08/2016.

A contribuição teórica deste estudo é quanto à aplicação do conhecimento sobre evasão universitária em cursos à distância e a contribuição prática está em poder alimentar de informações úteis na tomada de decisão empresarial para adequação de seu sistema de ensino para que seus alunos sejam retidos e possam concluir o ensino superior.

\section{REFERENCIAL TEÓRICO}

O referencial teórico deste trabalho apresenta os conceitos de evasão, de ensino à distância e os relaciona de maneira a lançar a luz sobre o tema Evasão no ensino à distância.

\section{A EVASÃO}

A Evasão escolar tem sido tema de diversos estudos no Brasil sendo que a partir de 1972, o assunto começou a despertar a preocupação das Universidades Públicas e o interesse do Ministério da Educação. Adachi (2009) define evasão como a saída definitiva do aluno de seu curso de origem. Segundo Baggi e Lopes (2010), é um problema que vem preocupando as instituições de ensino em geral, sejam públicas ou particulares, pois a saída dos alunos provoca graves consequências sociais, acadêmicas e econômicas.

Fialho (2014), em seu estudo, apresenta que, além dessas consequências, a evasão atinge os estudantes, a instituição e o governo, e altera os aspectos emocionais, psicológicos, humanos e financeiros refletindo direta e indiretamente na sociedade, provocando assim perda de capital humano elevando o desemprego e desigualdade social.

Baggi e Lopes (2010) realizaram uma pesquisa entre 2008 e 2009 para verificar os sentidos dos conceitos de evasão e saber até que ponto estariam sendo discutidos. Perceberam que a evasão tem múltiplas razões, pode estar relacionada diretamente a má qualidade de ensino oferecida pela Instituição ao contexto social, cultural, político e econômico em que está inserida.

A Comissão de Estudos sobre Evasão (1996) caracteriza a evasão em três formas:

- Evasão de curso: o desligamento do estudante do curso superior em várias situações como: abandono (não faz matrícula), desistência, transferência ou mudança de curso, exclusão por norma institucional;

- Evasão da Instituição: quando o estudante faz o desligamento da instituição em que está matriculado;

- Evasão do sistema: quando o estudante abandona o ensino superior de forma definitiva ou temporariamente.

\section{EVASÃO NO ENSINO SUPERIOR}

A evasão universitária tem levado muitos estudiosos a pesquisar seus motivos, a fim de encontrar alternativas para as razões que levam a este processo. Todos os autores opinam igualmente que as instituições de ensino superior devem adotar processos de gestão para que seja feita a prevenção da evasão, reduzindo assim os índices de abandono. E para este processo, é fundamental a compreensão dos fatores que levam a evasão.

A pesquisa de Polydoro (2000) teve por objetivo analisar os trancamentos de matricula que se refere às condições envolvidas na saída e no retorno do estudante à Instituição. Os principais motivos apresentados da evasão desses alunos foram: financeiros, relacionados ao trabalho, integração acadêmica, e a falta de motivação com o curso. Conforme a autora, os alunos pretendiam concluir seus cursos, sendo $64,25 \%$ na mesma Instituição e 56,4\% no mesmo 
curso. Esses alunos relacionaram o trancamento de matricula a uma oportunidade de rever sua decisão e manter um vínculo com a Instituição.

Veloso (2002) realizou sua pesquisa sobre a evasão na Universidade Federal de Mato Grosso, Campus de Cuiabá em todos os cursos oferecidos de graduação. O estudo se caracterizou como estudo de caso de abordagem qualitativa e quantitativa. A análise mostrou que os maiores índices de evasão estão nas áreas de Ciências Exatas e da Terra com 67,74\% e os menores índices de evasão são de Ciências Sociais e Aplicadas com 19,71\%. Já na análise dos dados do questionário aplicado aos Coordenadores dos cursos de graduação, com as observações feitas por eles, foram identificados cinco fatores de evasão, sendo eles:

- O aluno e sua contribuição: apresentam como contribuição para a evasão o aluno ser indeciso em sua escolha do curso por não conhecer e não ter informações e logo sua expectativa não é correspondida durante a permanência no curso, pois ainda falta maturidade.

- A estrutura física: indicam a falta de espaço físico, em termos de construção e conservação.

- A estrutura do curso: destacam o horário de funcionamento e a metodologia utilizada.

- Mercado de trabalho: nas respostas dos Coordenadores foram identificadas as diferenças entre o curso de Bacharelado que tem um quadro otimista para o mercado de trabalho, os de Licenciatura possuem um quadro diferenciado representado pela desvalorização da docência.

- O docente: foi destacado que o docente no processo de evasão tem um papel fundamental na manutenção do curso e ao atendimento ao aluno.

Os resultados da pesquisa de Veloso (2002) salientam que a participação do aluno evadido em pesquisas é fundamental, pois ele pode revelar suas expectativas e dificuldades, indicando também que o processo de evasão do aluno é reflexo da ausência de uma política de permanência no curso de sua opção.

Ataíde et al. (2006) ressaltaram que os problemas socioeconômicos, psicológicos, de ambientes familiares, questões culturais, as redes de relações, organizações estruturais e curriculares, ações metodológicas e pedagógicas, dentro outros são fatores que influenciam na desistência do acadêmico de cursar ensino superior. Barcelos (2012) apresenta que grande parcela dos estudantes tem dificuldades com as disciplinas do curso pelo fato de principalmente trabalharem e que é necessário a Instituição buscar meios para auxiliar esses estudantes por meio de ofertas de bolsas financeiras, grupos de estudos para minimizar as dificuldades com as disciplinas como ações para minimizar a evasão.

Apresentados estudos sobre evasão no ensino superior presencial, passa-se a caracterizar o ensino à distância e logo depois a evasão no ensino superior à distância.

\section{ENSINO À DISTÂNCIA}

Segundo Preti (2011), o ensino à distância (EAD) foi implementado na crise estrutural do capitalismo, da conjuntura econômica, política e tecnológica. Passou a ser utilizada como estratégia para qualificação de adultos, na contenção de gastos de serviços educacionais e que o conhecimento está ao alcance de todos. Após passar por pré-conceitos quanto ao ensino à distância, a atual conjuntura encontrou uma alternativa economicamente viável contando com novas tecnologias da informação e comunicação.

A Universidade Virtual, entendida como ensino superior e à distância com uso intensivo de Novas Tecnologias de Comunicação e Informação - NTIC, em especial a Internet e videoconferência, traz, em si, uma nova leitura no conceito da Educação à distância. $\mathrm{O}$ fenômeno do uso da internet e da videoconferência surge no Brasil na década de 1990, quando 
emerge também o ensino superior à distância (MAIA, 2003). Porém, surgiu primeiramente na Europa e, em seguida, no Canadá, nos Estados Unidos e na Austrália, segundo Preti (2011).

Segundo Mill (2013), em geral, a interlocução é possibilitada tanto por suportes tecnológicos para a comunicação síncrona/simultânea (como em web-conferências, salas de bate papo, etc.), quanto para comunicação assíncrona/diferida (a exemplo de fóruns, ferramentas para edição de textos web e e-mails). Em suma, a educação à distância é uma modalidade educacional que faz uso intensivo de tecnologias telemáticas (baseadas nas telecomunicações e na informática) e tem grande potencial para atender a pessoas em condições desfavoráveis para participação de cursos de graduação presenciais, geralmente oferecidos em grandes centros de ensino superior.

Apesar do grande interesse dos alunos pelos cursos à distância nos últimos anos pelos seus benefícios e vantagens, ainda há graves lacunas de conhecimentos dessa área, e dessa forma se fazem necessárias novas análises e discussões sobre as causas da evasão nessa modalidade de ensino, o que será tratado no próximo tópico.

\section{EVASÃO NO ENSINO À DISTÂNCIA}

Abbad et al. (2006) ressaltam a importância dos cursos à distância e que há poucas pesquisas que avaliam esses cursos e os índices de evasão. A pesquisa teve por objetivo identificar as variáveis de evasão de um curso gratuito oferecido a nível nacional à distância. Os resultados apresentam que os alunos que não concluem os cursos tendem a não utilizar os recursos de interação (chats, troca de mensagens eletrônicas, mural de notícias).

Walter (2008) analisou o comportamento e atitudes do aluno em relação ao curso à distância com a variável critério evasão dos alunos do Centro de Educação Tecnológica MSD Escola Aberta em parceria com a Confederação das Associações Comerciais e Empresarias do Brasil (CABD). Os resultados indicaram que os indivíduos que já haviam participado de cursos à distância foram os que menos evadiram dos cursos; que indivíduos que responderam aos fatores positivos intrínsecos e extrínsecos aos cursos foram os que menos evadiram e que os alunos que mais indicaram fatores desfavoráveis relacionados aos cursos foram os que mais evadiram.

Silveira (2012) indica que a modalidade do curso à distância está em grande expansão nas Instituições de Ensino Superior e que este processo acaba instigando a investigação de como está sendo desenvolvido esse processo. A grande mudança que vem ocorrendo neste momento educacional com o uso das Tecnologias de Informação e Comunicação no ensino justifica a importância de realizar a pesquisa proposta, tendo em vista que o uso da tecnologia no ensino é considerado uma dificuldade por muitos alunos e até motivo de desistência do curso.

Lacerda (2013) estudou o motivo de os estudantes deixarem o curso de Licenciatura em Ciências Biológicas do polo de educação à distância Cederj/UAB em Nova Friburgo - RJ com alunos evadidos de 2006 a 2011. Sem seus resultados, o questionamento sobre os motivos de desistência do curso levou a oito categorias de respostas, sendo elas:

- Ingresso em outro curso superior

- Problemas pessoais

- Dificuldade em conciliar o trabalho com o curso

- Dificuldade em se adaptar ao ensino semipresencial

- Desinteresse pelo curso

- Distância da Universidade

- Dificuldade com as disciplinas

- Críticas à estrutura do curso

Foi verificado por Lacerda (2013) que os fatores que levam os alunos a desistirem do curso nem sempre estão sujeitos ao controle da Instituição. É o caso de alunos que se inscrevem em mais de um curso e acabam desistindo de um deles e que a evasão para o ingresso em outro 
curso de ensino superior foi à principal justificativa para a desistência do curso de Ciências Biológicas.

Dessa maneia, foi proposta a realização dessa pesquisa para descobrir quais as principais razões de evasão em uma universidade de ensino à distância localizada no município de Rondonópolis - MT, considerando os aspectos demográficos dos alunos como uma forma de ampliar as discussões.

\section{PROCEDIMENTOS METODOLÓGICOS}

A principal motivação para realização dessa pesquisa foi descobrir as razões que levam os alunos de uma universidade de ensino à distância, sendo um polo de apoio localizada em Rondonópolis com sua matriz em Campo Grande - MS, deixarem seus cursos incluindo discussões sobre os aspectos demográficos.

Este trabalho teve por objetivo analisar as principais razões de evasão nos cursos de Administração, Ciências Contábeis, Serviço Social, Engenharia de Produção, Educação Física, Pedagogia, Gestão Pública, Gestão Comercial, Gestão Ambiental, Gestão Financeira, Gestão Hospitalar, Logística, Marketing, Recursos Humanos, Processos Gerenciais, Estética e Imagem Pessoal, Letras e Matemática do polo de educação à distância da Anhanguera Uniderp na cidade de Rondonópolis - MT a partir de dados demográficos de seus alunos. Os objetivos específicos foram:

- Comparar à variável gênero e as razões de evasão;

- Comparar à variável moradia e as razões de evasão;

- Comparar à variável situação e as razões de evasão;

- Comparar estado civil e as razões de evasão;

- Comparar à variável semestre e as razões de evasão;

- Comparar à variável curso e as razões de evasão;

Como parte da pesquisa foram geradas as seguintes hipóteses:

H1. Há diferenças entre as razões de evasão de acordo com o gênero;

H2. Há diferenças entre as razões de evasão e a moradia;

H3. Há diferenças entre as razões de evasão e a situação do aluno quando estava estudando;

H4. Há diferenças entre as razões de evasão e os semestres em que os alunos deixaram o curso;

H5. Há diferenças entre as razões de evasão e o estado civil;

H6. Há diferenças entre as razões de evasão e o curso em que o aluno estava matriculado;

Para este estudo, foram adotados os métodos qualitativos e quantitativos. Na primeira fase da pesquisa foram realizadas as entrevistas os coordenadores e o Diretor da Universidade e a partir de um roteiro semiestruturado com as cinco perguntas sobre o tema evasão e as possíveis razões. Após a realização das entrevistas o questionário eletrônico foi formulado baseando-se nas pesquisas de Cunha (2014), Netto et. al. (2012) e Nagai (2015).

O público alvo foi de alunos registrados entre os anos de 2007 que foi o ano de abertura da Universidade na cidade a 2016 em todos os cursos oferecidos na Universidade e que não estavam matriculados até julho de 2016, e que não haviam concluído o curso, totalizando assim 321 alunos. A partir de uma escala Likert de 11 pontos, os alunos deveriam pontuar as razões que influenciaram em sua desistência do curso. As possíveis razões foram retiradas das entrevistas com os coordenadores e também de estudos anteriores.

O questionário foi incluído no software Qualtrics, e, assim que ficou pronto, foi realizado um pré-teste solicitando feedback para o aperfeiçoamento. Depois disso foi criada a versão final do questionário para ser enviado aos alunos. Os questionários foram enviados para os 321 alunos, mas cerca de 30\% dos e-mails apresentaram falha na entrega. Após um mês a 
pesquisa foi encerrada com 53 respostas e dessas respostas 9 não foram validadas na pesquisa por estarem parcialmente respondidas, o que resultou em 44 respostas validadas, ou $19,6 \%$ dos e-mails corretos.

Para o tratamento dos dados, foi utilizado o software SPSS 20 (Statistical Package Social Sciences). Foi utilizada a análise fatorial que, de acordo com Field (2009, p.553), é "uma técnica para identificar grupos ou agrupamentos de variáveis" e a análise de correlação. Além disso, foram realizadas com a aplicação de testes não paramétricos envolvendo as variáveis demográficas e as razões de evasão, por meio de comparações entre médias buscando apresentar diferenças estatisticamente significativas para cada uma das hipóteses lançadas. Após isso, foram analisadas as respostas das entrevistas e comparadas com as questões abertas respondidas pelos alunos em uma tentativa de categorização e discussão das descobertas.

No próximo tópico os dados são apresentados e são discutidos os resultados a fim de alcançar o objetivo da pesquisa.

\section{APRESENTAÇÃO E ANÁLISE E DISCUSSÃO DOS RESULTADOS}

Após rodar a análise fatorial, as 29 assertivas, que estavam agrupadas em 5 categorias, redistribuíram-se em oito fatores, mas dois fatores não explicavam no mínimo $40 \%$ de suas variâncias. Foram feitas novas análises fatoriais que resultou em seis categorias que juntas explicam $86,8 \%$ da variação total, excluindo-se as razões: Casamento, Motivos financeiros, Mudança de curso, Falta de tempo para dedicar aos estudos e Dificuldades de conciliar estudo e trabalho.

Como a pesquisa não atingiu a quantidade mínima de respondentes, foi feita também a análise fatorial de cada categoria, individualmente, pois, a análise de todas as assertivas não atingia o valor de KMO. Os resultados das análises fatoriais, por categoria, estão apresentados no Quadro 1 e, como pode ser observado, as categorias Pessoal, família e finanças apresentou um sig< $<0,05$ apontando que há uma diferença estatisticamente significativas nesta categoria.

Quadro 1. Análise fatorial por categoria

\begin{tabular}{|l|c|c|}
\hline \multicolumn{1}{|c|}{ Categorias } & KMO & Sig \\
\hline Estrutura do curso & 0,83 & 0,000 \\
\hline Mercado de trabalho e carreira & 0,807 & 0,000 \\
\hline Trabalho e Localidade & 0,795 & 0,000 \\
\hline Pessoal, família e finanças & 0,672 & 0,001 \\
\hline Outras razões & 0,716 & 0,000 \\
\hline
\end{tabular}

Fonte: a pesquisa

Algumas assertivas foram eliminadas, pois, apresentavam baixa comunalidade ou não aumentavam o poder explicativo dos fatores. Os seis fatores apresentaram separadamente um Alfa de Cronbach variando entre 0,595 e 0,943 quando calculados com todas suas assertivas. Após a eliminação de algumas assertivas os valores de Alfa de Cronbach passaram a variar de 0,691 a 0,943. No Quadro 2, são apresentados os resultados da análise fatorial das 24 assertivas e sua variância total explicada. 
Quadro 2. Análise Fatorial e Variância Total Explicada

\begin{tabular}{|c|c|c|c|c|c|c|}
\hline & \multicolumn{3}{|c|}{ Carga dos Fatores sem Rotação } & \multicolumn{3}{c|}{ Carga dos Fatores com Rotação } \\
\hline Componentes & Total & $\begin{array}{c}\% \text { de } \\
\text { Variância }\end{array}$ & $\begin{array}{c}\% \\
\text { Acumulada }\end{array}$ & Total & $\begin{array}{c}\% \text { de } \\
\text { Variância }\end{array}$ & $\begin{array}{c}\% \\
\text { Acumulada }\end{array}$ \\
\hline 1 & 10,103 & 42,098 & 42,098 & 7,599 & 31,662 & 31,662 \\
2 & 3,068 & 12,784 & 54,882 & 2,888 & 12,032 & 43,694 \\
3 & 2,767 & 11,529 & 66,411 & 2,833 & 11,804 & 55,499 \\
4 & 1,857 & 7,739 & 74,150 & 2,592 & 10,798 & 66,297 \\
5 & 1,629 & 6,787 & 80,937 & 2,583 & 10,764 & 77,060 \\
6 & 1,389 & 5,787 & 86,724 & 2,319 & 9,663 & 86,724 \\
\hline
\end{tabular}

Fonte: a pesquisa

O Quadro 3 mostra o reagrupamento das assertivas em 6 fatores de acordo com suas cargas fatoriais e utilizando-se da rotação varimax.

Quadro 3. Matriz de componentes com rotação Varimax

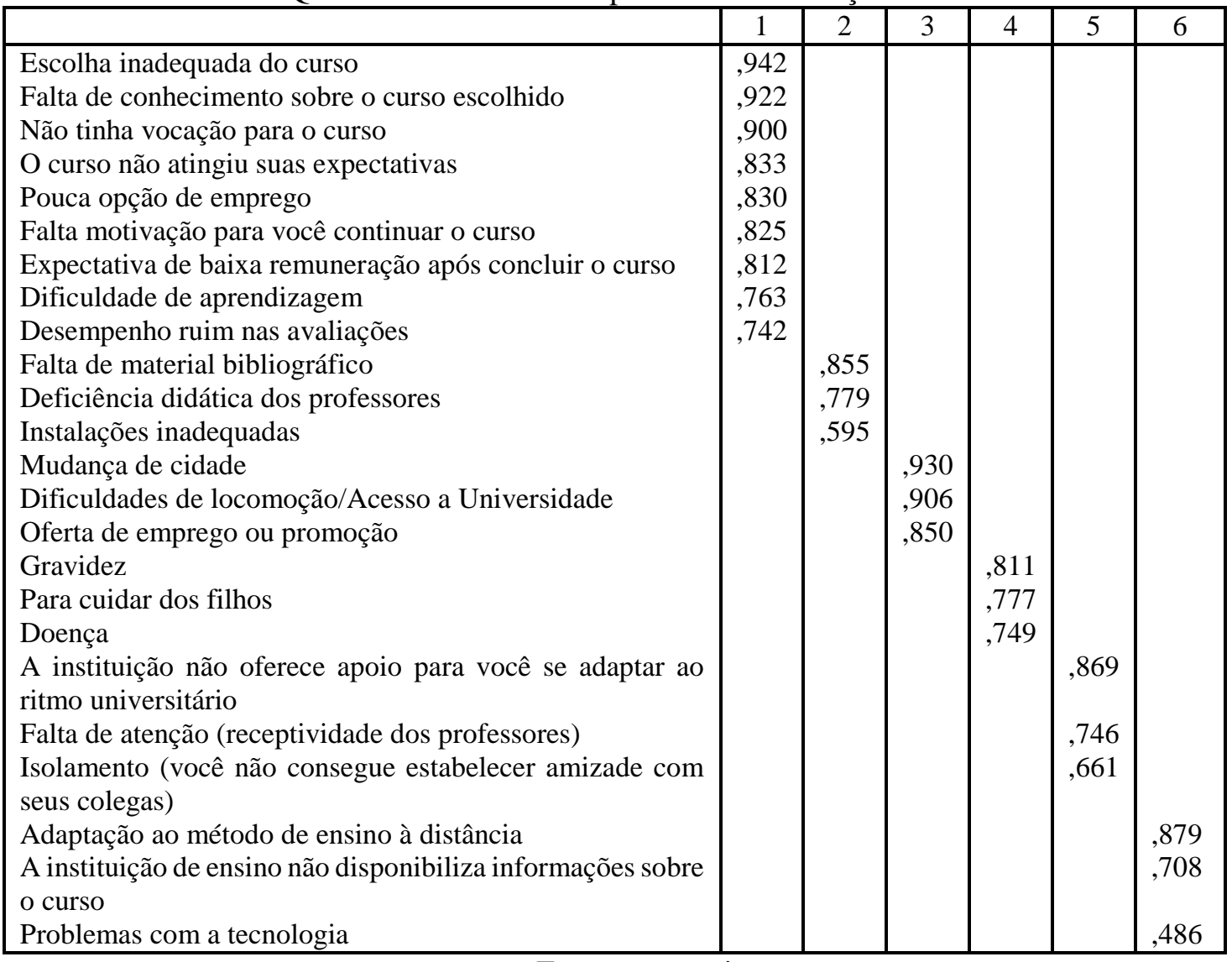

Fonte: a pesquisa

Como foi descoberto um novo fator, e outros se agruparam de maneira diferente, excluindo ou incluindo assertivas, fez-se necessária uma readequação na nomenclatura dos fatores anteriores. A partir da análise foi possível identificar que os fatores Mercado de Trabalho, Outras razões, Pessoal, família e finanças, que anteriormente estavam agrupados, foram divididos em fatores singulares. Também surgiu um fator novo não percebido anteriormente, como é o caso do fator Método à distância.

O Quadro 4 apresenta os cinco fatores com suas nomenclaturas, as assertivas que os compõe e medida de confiabilidade com o Alfa de Cronbach. Retrata como os dados ficaram 
distribuídos em cada Fator e os parâmetros de confiabilidade e qualidade da escala (Alfa de Cronbach) o que propicia as análises subsequentes a fim de testar as hipóteses de pesquisa, atender aos objetivos específicos e responder aos problemas de pesquisa deste estudo.

A redução das razões de evasão para 24 assertivas distribuídas em 5 fatores, e tendo em vista os parâmetros de qualidade e confiabilidade dos dados apresentados, propicia as análises seguintes a fim de testar as hipóteses de pesquisa e atender aos objetivos específicos.

A partir da redistribuição dos fatores foram realizados os testes de normalidade e homogeneidade para identificação de qual tipo de teste (paramétrico ou não paramétrico) deve se proceder para análise de correlação e o comparativo entre as médias. Conforme apresentado no Quadro 5, os resultados indicaram não haver normalidade dos dados da distribuição para alguns fatores $(\operatorname{sig}<0,05)$, e haver homogeneidade da variância da distribuição dos fatores (sig>0,05). Dessa forma, foi realizado o teste não paramétrico de correlação de Spearman, e os comparativos de média usando os testes não paramétricos de Mann-Whitney e o de KruskallWallis.

Quadro 4. Fatores influenciadores da evasão

\begin{tabular}{|c|c|c|}
\hline Fatores & Assertivas & $\begin{array}{c}\text { Alfa } \\
\text { Cronbach }\end{array}$ \\
\hline \multirow{9}{*}{$\begin{array}{l}\text { Mercado de } \\
\text { trabalho e curso }\end{array}$} & Escolha inadequada do curso & \multirow{9}{*}{,943 } \\
\hline & Falta de conhecimento sobre o curso escolhido & \\
\hline & Não tinha vocação para o curso & \\
\hline & O curso não atingiu suas expectativas & \\
\hline & Pouca opção de emprego & \\
\hline & Falta motivação para você continuar o curso & \\
\hline & Expectativa de baixa remuneração após concluir o curso & \\
\hline & Dificuldade de aprendizagem & \\
\hline & Desempenho ruim nas avaliações & \\
\hline \multirow{6}{*}{ Estrutura do curso } & Falta de material bibliográfico & \multirow{6}{*}{876} \\
\hline & Deficiência didática dos professores & \\
\hline & Instalações inadequadas & \\
\hline & $\begin{array}{l}\text { A instituição não oferece apoio para você se adaptar ao ritmo } \\
\text { universitário }\end{array}$ & \\
\hline & Falta de atenção (receptividade) dos professores & \\
\hline & $\begin{array}{l}\text { Isolamento (você não consegue estabelecer amizade com seus } \\
\text { colegas) }\end{array}$ & \\
\hline \multirow{3}{*}{$\begin{array}{l}\text { Trabalho e } \\
\text { Localidade }\end{array}$} & Mudança de cidade & \multirow{3}{*}{,753 } \\
\hline & Dificuldades de locomoção/Acesso a Universidade & \\
\hline & Oferta de emprego ou promoção & \\
\hline \multirow[t]{3}{*}{ Problemas pessoais } & Gravidez & \multirow{3}{*}{825} \\
\hline & Para cuidar dos filhos & \\
\hline & Doença & \\
\hline \multirow{3}{*}{ Método à distância } & Adaptação ao método de ensino a distancia & \multirow{3}{*}{691} \\
\hline & $\begin{array}{l}\text { A instituição de ensino não disponibiliza informações sobre o } \\
\text { curso }\end{array}$ & \\
\hline & Problemas com a tecnologia & \\
\hline
\end{tabular}

Fonte: a pesquisa 
Quadro 5. Teste de Normalidade e Homogeneidade

\begin{tabular}{|c|c|c|c|c|c|c|c|c|}
\hline \multicolumn{5}{|c|}{ Teste de Normalidade - Kolmogorov-Smirnov } & \multicolumn{4}{|c|}{ Teste de Homogeneidade da Variância } \\
\hline & Gênero & Statistic & $\mathrm{df}$ & Sig. & Levene & df1 & df2 & Sig. \\
\hline \multirow{2}{*}{$\begin{array}{c}\text { Mercado de trabalho e } \\
\text { curso }\end{array}$} & Masculino & 0,181 & 10 & ,200* & \multirow{2}{*}{2,8} & \multirow{2}{*}{1} & \multirow{2}{*}{17} & \multirow{2}{*}{0,113} \\
\hline & Feminino & 0,143 & 9 & $200 *$ & & & & \\
\hline \multirow{2}{*}{ Estrutura do curso } & Masculino & 0,261 & 10 & 0,052 & \multirow{2}{*}{0,433} & \multirow{2}{*}{1} & \multirow{2}{*}{17} & \multirow{2}{*}{0,52} \\
\hline & Feminino & 0,218 & 9 & ,200* & & & & \\
\hline \multirow{2}{*}{ Trabalho e Localidade } & Masculino & 0,184 & 10 & ,200* & \multirow{2}{*}{0,49} & \multirow{2}{*}{1} & \multirow{2}{*}{17} & \multirow{2}{*}{0,827} \\
\hline & Feminino & 0,311 & 9 & 0,012 & & & & \\
\hline \multirow{2}{*}{ Problemas Pessoais } & Masculino & 0,315 & 10 & 0,006 & \multirow{2}{*}{1,874} & \multirow{2}{*}{1} & \multirow{2}{*}{17} & \multirow{2}{*}{0,189} \\
\hline & Feminino & 0,321 & 9 & 0,008 & & & & \\
\hline \multirow{2}{*}{ Método à distância } & Masculino & 0,205 & 10 & ,200* & \multirow{2}{*}{0,84} & \multirow{2}{*}{1} & \multirow{2}{*}{17} & \multirow{2}{*}{0,372} \\
\hline & Feminino & 0,229 & 9 & 0,189 & & & & \\
\hline
\end{tabular}

Fonte: a pesquisa

O Quadro 6 exibe os resultados de correlação entre os fatores e as variáveis demográficas: Estado civil, curso, semestre, situação quando estudava, moradia e gênero.

Pode-se observar que há correlação positiva a um nível de significância 0,05 entre a variável Estado civil com os fatores Situação quando estudava, moradia, mercado de trabalho e curso, e correlação negativa com o fator Método à distância. A variável gênero apresentou correlação negativa de significância de 0,05 com o fator curso. A moradia apresenta uma correlação negativa a um nível de significância de 0,05 com o fator Mercado de trabalho e curso.

A variável semestre não se apresenta significativamente correlacionada a um nível de significância de 0,05 a nenhum dos fatores. E foi possível também notar que diversos fatores apresentam com frequência negativa e positiva entre si.

Quadro 6. Dados de análise de correlação de Spearman

\begin{tabular}{|l|c|c|c|c|c|c|}
\hline \multirow{3}{*}{ Correlação } & Estado Civil & Curso & Semestre & $\begin{array}{c}\text { Situação } \\
\text { quando } \\
\text { Estudava }\end{array}$ & Moradia & Gênero \\
\hline \multirow{2}{*}{ Mercado de trabalho e curso } &,$- 554^{* *}$ & $-0,17$ & 0,319 &,$- 378^{*}$ & $-0,226$ & $-0,065$ \\
\cline { 2 - 7 } & 0 & 0,329 & 0,058 & 0,023 & 0,184 & 0,707 \\
\hline \multirow{2}{*}{ Estrutura do curso } & $-0,207$ & 0,038 & 0,177 & $-0,228$ & 0,008 & $-0,003$ \\
\cline { 2 - 7 } & 0,239 & 0,834 & 0,317 & 0,195 & 0,965 & 0,986 \\
\hline \multirow{2}{*}{ Trabalho e Localidade } & 0,06 & 0,012 & 0,271 & $-0,232$ & 0,094 & $-0,142$ \\
\cline { 2 - 7 } & 0,736 & 0,948 & 0,12 & 0,186 & 0,595 & 0,422 \\
\hline \multirow{2}{*}{ Problemaspessoais } & 0,229 & $-0,009$ & $-0,104$ & $-0,066$ & $-0,02$ & $-0,009$ \\
\hline \multirow{2}{*}{ Método à distância } & 0,332 & 0,971 & 0,661 & 0,782 & 0,935 & 0,678 \\
\cline { 2 - 7 } &,$- 390^{*}$ & 0,033 & 0,006 & $-0,268$ & $-0,211$ & 0,011 \\
\hline
\end{tabular}

Fonte: a pesquisa

A seguir, são discutidos os resultados de acordo com cada hipótese anteriormente elaborada.

H1. Há diferenças entre as razões de evasão de acordo com o gênero;

Quanto à variável gênero, como pode ser observada no Quadro 7, não apresenta diferenças estatisticamente significativas $(\operatorname{sig}<0,05)$ com nenhum dos fatores. Dessa forma, a primeira hipótese não foi confirmada, ou seja, não há relação entre a variação de gênero a uma 
variação de fatores influenciadores de evasão e não há diferenças estatisticamente significativas (a um nível de 0,05) entre gênero e fatores de evasão.

Quadro 7. Comparações entre os gêneros - Teste de Mann-Whitney

\begin{tabular}{|l|c|c|c|c|c|}
\hline & $\begin{array}{c}\text { Mercado de } \\
\text { trabalho e } \\
\text { curso }\end{array}$ & $\begin{array}{c}\text { Estrutura do } \\
\text { curso }\end{array}$ & $\begin{array}{c}\text { Trabalho e } \\
\text { Localidade }\end{array}$ & $\begin{array}{c}\text { Problemas } \\
\text { pessoais }\end{array}$ & $\begin{array}{c}\text { Método à } \\
\text { distância }\end{array}$ \\
\hline Mann-Whitney U & 148,000 & 142,000 & 121,000 & 44,000 & 158,000 \\
Wilcoxon W & 358,000 & 332,000 & 292,000 & 89,000 & 294,000 \\
Z &,- 383 &,- 018 &,- 817 &,- 432 &,- 064 \\
Asymp. Sig. (2-tailed) &, 701 &, 986 &, 414 &, 666 &, 949 \\
ExactSig. [2*(1-tailed Sig.)] &, $718^{\mathrm{b}}$ & $1,000^{\mathrm{b}}$ &, $443^{\mathrm{b}}$ &, $710^{\mathrm{b}}$ &, $962^{\mathrm{b}}$ \\
\hline
\end{tabular}

Fonte: a pesquisa

H2. Há diferenças entre as razões de evasão e a moradia;

A variável moradia apresenta que há correlação a um nível de significância de $0,05 \mathrm{com}$ o fator Método à distância. Dessa forma, pode-se perceber que a moradia afeta na decisão de deixar o curso, e que há diferenças estatisticamente significativas (a um nível de 0,05 ) entre a moradia e o fator Método à distância, conforme confirmam os dados no Quadro $8(\operatorname{sig}<0,05)$.

Quadro 8. Comparações entre moradia - Teste de Kruskal-Wallis

\begin{tabular}{|l|c|c|c|c|c|}
\hline & $\begin{array}{c}\text { Mercado de } \\
\text { trabalho e curso }\end{array}$ & $\begin{array}{c}\text { Estrutura do } \\
\text { curso }\end{array}$ & $\begin{array}{c}\text { Trabalho e } \\
\text { Localidade }\end{array}$ & $\begin{array}{c}\text { Problemas } \\
\text { pessoais }\end{array}$ & $\begin{array}{c}\text { Método à } \\
\text { distância }\end{array}$ \\
\hline Chi-Square & 4,966 & 1,447 & 1,692 & 4,072 & 6,462 \\
DF & 2 & 2 & 2 & 2 & 2 \\
Asymp. Sig. &, 083 &, 485 &, 429 &, 131 &, 040 \\
\hline
\end{tabular}

Fonte: a pesquisa

H3. Há diferenças entre as razões de evasão e a situação quando estudava;

A variável situação quando estava estudando revela que há diferenças estatisticamente significativas entre situação quando estava estudando para o fator Mercado de trabalho e curso. O teste não paramétrico de Kruskall-Wallis apresentado no Quadro 9 confirma a hipótese 3, indicando que há diferenças estatisticamente significativas entre o fator Mercado de trabalho e curso e a variável situação quando estudava.

Quadro 9. Comparações entre situação quando estudava - Teste de Kruskal-Wallis

\begin{tabular}{|l|c|c|c|c|c|}
\hline & $\begin{array}{c}\text { Mercado de } \\
\text { trabalho e curso }\end{array}$ & $\begin{array}{c}\text { Estrutura do } \\
\text { curso }\end{array}$ & $\begin{array}{c}\text { Trabalho e } \\
\text { Localidade }\end{array}$ & $\begin{array}{c}\text { Problemas } \\
\text { pessoais }\end{array}$ & $\begin{array}{c}\text { Método à } \\
\text { distância }\end{array}$ \\
\hline Chi-Square & 8,155 & 4,879 & 3,083 &, 981 & 3,776 \\
DF & 2 & 2 & 2 & 2 & 2 \\
Asymp. Sig. &, 017 &, 087 &, 214 &, 612 &, 151 \\
\hline
\end{tabular}

Fonte: a pesquisa

H4. Há diferenças entre as razões de evasão e o estado civil;

Aplicando-se o Teste de Kruskall-Wallis foi possível perceber no Quadro 10 que há diferenças estatisticamente significativas entre a variável Estado civil e os fatores Mercado de trabalho e curso e Método à distância. 
Quadro 10. Comparações entre estado civil - Teste de Kruskal-Wallis

\begin{tabular}{|l|c|c|c|c|c|}
\hline & $\begin{array}{c}\text { Mercado de } \\
\text { trabalho e } \\
\text { curso }\end{array}$ & $\begin{array}{c}\text { Estrutura do } \\
\text { curso }\end{array}$ & $\begin{array}{c}\text { Trabalho e } \\
\text { Localidade }\end{array}$ & Problemaspessoais & $\begin{array}{c}\text { Método à } \\
\text { distância }\end{array}$ \\
\hline Chi-Square & 9,127 & 3,002 &, 385 &, 994 & 5,761 \\
DF & 1 & 2 & 1 & 1 & 1 \\
Asymp. Sig. &, 003 &, 223 &, 535 &, 319 &, 016 \\
\hline
\end{tabular}

Fonte: a pesquisa

Dessa forma, a hipótese 4 é corroborada indicando que há diferenças estatisticamente significativas entre as razões de evasão e o estado civil dos alunos.

H5. Há diferenças entre as razões de evasão e os semestres em que os alunos;

A variável semestres não apresentou correlação a um nível de significância de $0,05 \mathrm{em}$ nenhum dos fatores. Pode-se observar no Quadro 11 que, ao aplicar o teste de Kruskal-Wallis, não há diferenças estatisticamente significativas (a um nível de 0,05 ) entre semestre os fatores de evasão $($ sig $>0,05)$.

Quadro 11.Comparações entre os semestres - Teste de Kruskal-Wallis

\begin{tabular}{|l|c|c|c|c|c|}
\hline & $\begin{array}{c}\text { Mercado de } \\
\text { trabalho e curso }\end{array}$ & $\begin{array}{c}\text { Estrutura do } \\
\text { curso }\end{array}$ & $\begin{array}{c}\text { Trabalho e } \\
\text { Localidade }\end{array}$ & $\begin{array}{c}\text { Problemas } \\
\text { pessoais }\end{array}$ & $\begin{array}{c}\text { Método à } \\
\text { distância }\end{array}$ \\
\hline Chi-Square & 9,341 & 10,617 & 4,998 & 1,811 & 8,961 \\
DF & 6 & 6 & 6 & 5 & 6 \\
Asymp. Sig. &, 155 &, 101 &, 544 &, 875 &, 176 \\
\hline
\end{tabular}

Fonte: a pesquisa

Dessa forma, a hipótese 5 não é corrobora indicando que não há diferenças estatisticamente significativas entre as razões de evasão e os semestres que os alunos deixam seus cursos.

H6. Há diferenças entre as razões de evasão de acordo com o curso;

A variável Curso apresentou não ter correlação a um nível de significância de 0,05 a nenhum dos fatores. Mesmo assim, após aplicar teste de Kruskal-Wallis, confirma-se que não há diferenças estatisticamente significativas (a um nível de 0,05 ) entre os cursos e os fatores de evasão (sig>0,05), conforme Quadro 12.

Quadro 12. Comparações entre os cursos - Teste de Kruskal-Wallis

\begin{tabular}{|l|c|c|c|c|c|}
\hline & $\begin{array}{c}\text { Mercado de } \\
\text { trabalho e curso }\end{array}$ & $\begin{array}{c}\text { Estrutura do } \\
\text { curso }\end{array}$ & $\begin{array}{c}\text { Trabalho e } \\
\text { Localidade }\end{array}$ & $\begin{array}{c}\text { Problemas } \\
\text { pessoais }\end{array}$ & $\begin{array}{c}\text { Método à } \\
\text { distância }\end{array}$ \\
\hline Chi-Square & 6,086 & 7,105 & 5,806 & 2,590 & 6,425 \\
DF & 7 & 6 & 7 & 3 & 7 \\
Asymp. Sig. &, 530 &, 311 &, 563 &, 459 &, 491 \\
\hline
\end{tabular}

Fonte: a pesquisa

Dessa forma, a hipótese 6 não corrobora indicando que não há diferenças estatisticamente significativas entre as razões de evasão e os cursos.

Após a análise dos dados quantitativos, resumidos no Quadro 13, busca-se uma análise qualitativa para poder ampliar as discussões quanto às descobertas. 
Quadro 13. Síntese das análises das hipóteses

\begin{tabular}{|l|l|}
\hline H1 & $\begin{array}{l}\text { A primeira hipótese não foi confirmada, não houve relação entre a variável Gênero e os fatores } \\
\text { influenciadores de evasão. }\end{array}$ \\
\hline H2 & $\begin{array}{l}\text { A segunda hipótese foi confirmada, houve a descoberta que a Moradia afeta na decisão de deixar o curso } \\
\text { com o fator Método à distância. }\end{array}$ \\
\hline H3 & $\begin{array}{l}\text { A terceira hipótese foi confirmada, houve a descoberta que a variável Situação quando estudava afeta } \\
\text { na decisão de deixar o curso com o fator Mercado de trabalho e curso. }\end{array}$ \\
\hline H4 & $\begin{array}{l}\text { A quarta hipótese foi confirmada, houve a descoberta que a variável Estado civil afeta na decisão de } \\
\text { deixar o curso com os fatores Mercado de trabalho e curso e o Método à distância. }\end{array}$ \\
\hline H5 & $\begin{array}{l}\text { A quinta hipótese não foi confirmada, não houve relação entre a variável Semestre e os fatores } \\
\text { influenciadores de evasão. }\end{array}$ \\
\hline H6 & A sexta hipótese não foi confirmada, não houve relação entre a variável Curso e os fatores de evasão. \\
\hline
\end{tabular}

Fonte: a pesquisa

\section{DADOS QUALITATIVOS}

Conforme informado, o questionário foi enviado aos 321 ex-alunos evadidos disponibilizando uma questão aberta sobre porque decidiu realizar o curso a distância, e 39 responderam a essa pergunta aberta. A mesma pergunta foi feita para os coordenadores e para o Diretor da Universidade. A partir da leitura das respostas, foi elaborado um quadro com a identificação das categorias e suas verbalizações. Os temas foram agrupados em cinco categorias-síntese: Tempo; Financeiro; Praticidade; Acessibilidade e Outras razões e conforme também foi apresentado pelos autores Borges (2011) e Netto (2012).

As duas últimas categorias possuem apenas verbalizações dos ex-alunos, pois não foram identificados nas entrevistas, mas também acrescentam para a decisão de cursar no ensino à distância. Vários respondentes relataram a praticidade que foi agrupada como na categoria, outros relataram que a influência da família, a comodidade, a facilidade de estudar em casa e por haver o curso apenas nessa modalidade de ensino os levou a essa opção, conforme no Quadro 14.

Além desta pergunta aberta, havia outra pergunta onde os ex-alunos poderiam deixar um comentário. Com as últimas questões também foi possível identificar se o aluno teve dúvida na escolha do curso, se foi o primeiro ingresso no ensino superior e sua situação atual.

Após analisar os comentários, foi possível descobrir apenas uma nova razão de evasão que não estava no questionário e até citada como "provas muito mal formuladas". Outros pontos ressaltados foram a melhoria no atendimento, passar melhor as informações aos alunos, a falta de preparo dos tutores e seus problemas com os processos enviados à matriz da Universidade.

Em relação à dúvida na escolha do curso $52 \%$ responderam que não tiveram dúvidas e $48 \%$ responderam que $\operatorname{sim}, 85 \%$ responderam que foi o primeiro ingresso no ensino superior e $15 \%$ não, e a situação atual dos ex-alunos $54 \%$ não estudam, $32 \%$ estão na Universidade Federal, $10 \%$ estão em Instituições particulares e $2 \%$ continua na mesma Instituição. 
Quadro 14. Categorias-síntese com membros da universidade e alunos

\begin{tabular}{|c|c|c|}
\hline Categorias & $\begin{array}{l}\text { Visão dos Entrevistados } \\
\text { (Diretor e Coordenadores) }\end{array}$ & Visão dos alunos evadidos \\
\hline \multirow[t]{3}{*}{ TEMPO } & $\begin{array}{l}\text { "Por questão de tempo, as aulas são uma } \\
\text { vez na semana." }\end{array}$ & $\begin{array}{l}\text { "Devido à falta de tempo e } \\
\text { disponibilidade para frequentar o curso } \\
\text { presencial." }\end{array}$ \\
\hline & $\begin{array}{l}\text { "Acredito que seja pelo tempo que fica } \\
\text { acessível para eles." }\end{array}$ & "Pois teria tempo para trabalhar." \\
\hline & $\begin{array}{l}\text { "Optam por o curso tem uma flexibilidade } \\
\text { de horário por ser } 1 \text { vez na semana." }\end{array}$ & $\begin{array}{l}\text { "Pelo fato de trabalhar o dia todo, ir } \\
\text { apenas uma vez à faculdade era menos } \\
\text { cansativo." }\end{array}$ \\
\hline \multirow[t]{2}{*}{ FINANCEIRO } & $\begin{array}{l}\text { "Pela questão financeira, a universidade } \\
\text { tem a proposta de mensalidade baixa." }\end{array}$ & $\begin{array}{l}\text { "Porque o valor das mensalidades estava } \\
\text { bem acessível para mim em relação ao } \\
\text { valor do salário que eu ganhava." }\end{array}$ \\
\hline & $\begin{array}{l}\text { "A mensalidade que é abaixo dos cursos } \\
\text { presenciais." }\end{array}$ & $\begin{array}{l}\text { "Pela falta de tempo de ir todo o dia para } \\
\text { universidade e economicamente mais } \\
\text { viável." }\end{array}$ \\
\hline \multirow{3}{*}{ ACESSIBILIDADE } & $\begin{array}{l}\text { "Acessível, porque as aulas são apenas } \\
\text { uma vez por semana, então aqueles que } \\
\text { não têm tempo de assistir aulas todos os } \\
\text { dias, optam por fazer à distância." }\end{array}$ & $\begin{array}{l}\text { "Pois ser de mais fácil acesso! Devido o } \\
\text { serviço ser muito corrido, não consigo } \\
\text { estar todos os dias na faculdade!" }\end{array}$ \\
\hline & $\begin{array}{l}\text { "Acredito que seja pelo tempo que é } \\
\text { acessível a eles, aula apenas uma vez na } \\
\text { semana." }\end{array}$ & $\begin{array}{l}\text { "Fácil acesso ao campus e horários } \\
\text { alternativos de estudo." }\end{array}$ \\
\hline & $\begin{array}{l}\text { "Acessibilidade de ir à faculdade apenas } \\
\text { uma vez por semana e estudar em casa." }\end{array}$ & $\begin{array}{l}\text { "Facilidade no acesso ao material. } \\
\text { Facilidade em administrar meu tempo." }\end{array}$ \\
\hline PRATICIDADE & \multicolumn{2}{|l|}{$\begin{array}{l}\text { "Por praticidade." } \\
\text { "Por achar que seria mais prático." } \\
\text { "Praticidade e mensalidade barata." } \\
\text { "Pela praticidade, valor e acessibilidade." }\end{array}$} \\
\hline $\begin{array}{l}\text { OUTRAS } \\
\text { RAZÕES }\end{array}$ & \multicolumn{2}{|c|}{$\begin{array}{l}\text { "Influencia da família." } \\
\text { "Porque o curso de logística só oferecia a distancia." } \\
\text { "Pela comodidade." } \\
\text { "Pela facilidade de poder estudar em casa." }\end{array}$} \\
\hline
\end{tabular}

\section{CONSIDERAÇÕES FINAIS}

Como informado, o estudo tinha por objetivo analisar os motivos de evasão dos alunos de uma Universidade de ensino à distância. A análise de conteúdo das verbalizações dos alunos e dos entrevistados registrados nos comentários apontou que os motivos que levam esses alunos a optarem pelo ensino à distância podem ser agrupados em cinco categorias: tempo, financeiro, acessibilidade, praticidade e outras razões.

O presente estudo segue recomendações de pesquisas feitas por diversos autores como Abbad (2006), Walter (2008), Lacerda (2013), Silveira (2013) e Netto (2012) sobre a realização de estudos sobre cursos oferecidos a distância e evasão, foi possível perceber que existem diversos fatores que podem levar a evasão dos alunos no Ensino à distância.

Conforme os estudos realizados sobre o tema evasão, o fator financeiro é apresentado como um fator singular. Já nas pesquisas realizadas sobre a evasão no ensino à distância, este fator não foi representado como motivo de evasão. E na presente 
pesquisa a assertiva "problemas financeiros" foi eliminada após realizar a análise fatorial das categorias e por não influenciar na decisão dos alunos a deixar seus cursos.

Como a pesquisa não atingiu a quantidade mínima de respondentes para aplicação de uma análise fatorial com as assertivas, pois segundo Hair (2006), o mínimo seria de 5 respostas para cada assertiva, foi realizada uma análise fatorial de cada categoria individualmente. Mesmo reconhecendo ser uma limitação da pesquisa, com a análise individual os valores de KMO, alfa de Cronbach deram sustentação e confiabilidade para as análises seguintes.

Apenas as Hipóteses 2, 3 e 4 apresentam diferenças entre as razões de evasão e as variáveis demográficas, as demais variáveis demográficas e os fatores de evasão apresentaram NÃO haver diferenças estatisticamente significativas.

Foi descoberto um novo fator e outros se agruparam de maneira diferente, excluindo ou incluindo assertivas, assim se fez necessária uma readequação na nomenclatura dos fatores anteriores. A partir da análise foi possível identificar que os fatores Mercado de Trabalho, Outras razões, Pessoal que anteriormente estavam agrupados, foram divididos em fatores individuais. Também surgiu um fator novo não percebido anteriormente, como é o caso do fator Método à distância.

Por fim, pode-se dizer que este estudo contribui com a teoria quanto à ampliação do conhecimento sobre evasão universitária em cursos à distância e a contribuição prática está em poder alimentar de informações úteis para a tomada de decisão empresarial e adequação do sistema de ensino à distância para que os alunos sejam retidos e possam concluir o ensino superior

\section{REFERÊNCIAS}

ABBAD, G; CARVALHO, S. R; ZERBINI, T. Evasão em curso via internet: Explorando variáveis explicativas. RAE-eletrônica, v. 5, n. 2, Art. 17, jul./dez. 2006

ADACHI, A. A. C. T. Evasão e evadidos nos cursos de graduação da Universidade Federal de Minas Gerais. Belo Horizonte, 2009. 214 f. Dissertação - Mestrado em Educação, UFMG/FaE.

ATAÍDE, J. S. P.; LIMA, L. M.; ALVES, E. de O. A repetência e o abandono escolar no curso de licenciatura em física: um estudo de caso. Revista Physicae. v. 6. 2006.

BAGGI, C. A. dos S.; LOPES, D, A. Evasão e Avaliação Institucional no Ensino Superior: uma discussão bibliográfica. Avaliação, v. 16. N. 2, p. 355-374, jul. 2011.

BARCELOS, H. C.; RAIMANN, E. Análise evasão e reprovação universitária: uma análise a partir dos alunos do curso de sistemas de informação do IFG. $6^{\circ}$ Seminário de Iniciação Científica, Goiânia, 2012.

BORGES, S. M. Fatores determinantes da evasão escolar no ensino superior: o estudo de caso do ILES/ULBRA de Itumbiara. Goiânia, 2011. 77 f. Dissertação (mestrado), Programa de Pós-Graduação Stricto Sensu. Mestrado Profissional em Desenvolvimento Regional, Faculdades Alves Faria. 
COMISSÃO ESPECIAL DE ESTUDOS SOBRE EVASÃO (MEC/ANDIFES/ABRUEM/SESU). Diplomação, retenção e evasão nos cursos de graduação em instituições de ensino superior públicas. Brasília, 1996.

CUNHA, J. V. A.; NASCIMENTO, E. M.; DURSO, A. O. Razões e influencias para a evasão universitária:um estudo com estudantes ingressantes nos cursos de Ciências Contábeis de instituições públicas federais da Região Sudeste. São Paulo, 2014.

FIALHO, M. G. D.; PRESTES, E. M. Da T. Evasão escolar no curso de pedagogia da UFPB: na compreensão dos gestores educacionais. MPGOA, João Pessoa, v.3, n.1, p. 42-63, 2014.

FIELD, A. Descobrindo a estatística usando o SPSS. 2 ed. Porto Alegre. Artmed, 2009.

HAIR, J. F.Análise Multivariada de dados.Porto Alegre: Bookman, 2006.

LACERDA, F. K. D.; ESPÍNDOLA, R. M. Evasão na Educação à distância: Um estudo de caso. Nova Friburgo: Cedrj. 2013

MAIA, CARMEN.;EAD.BR: Experiências inovadoras em educação a distância no Brasil reflexões, em tempo real.São Paulo.2003.

MILL, D; MACIEL, C. Educação à Distância: Elementos para pensar o Ensino Aprendizagem Contemporâneo.Cuiabá.EdUFMT. 2013.

NAGAI, P. N. A Evasão Universitária: Uma análise além dos números. Rondonópolis: UFMT. 2015

NETTO, C.; GUIDOTTI, V.; SANTOS, P. K. A Evasão na EAD: Investigando Causas, Proprondo estratégias. Rio Grande do Sul, 2012.

POLYDORO, S. A. J. O trancamento de matrícula na trajetória acadêmica do universitário: condições de saída e retorno à instituição. Faculdade de Educação UNIC16AMP, (Tese de Doutorado), 2000.

PRETI, O. Educação à distância: Fundamentos e políticas. Cuiabá.EdUFMT.2011.

SILVEIRA, C. A. B. Educação à e a evasão: Estudo de caso da realidade no polo UAB de Franca.São Carlos.2012.

VELOSO, T. C. M. A.; ALMEIDA, E. P. Evasão nos cursos de graduação da Universidade Federal de Mato Grosso, campus universitário de Cuiabá: Um processo de exclusão. Cuiabá: UFMT. 2002.

WALTER, A. M; ABBAD, G. S. Variáveis preditoras de evasão em dois cursos à distância.Rio de Janeiro. 2008. 